\title{
Conditioned flavour aversions in sheep: the relationship between the dose rate of a secondary plant compound and the acquisition and persistence of aversions
}

\author{
I. Kyriazakis ${ }^{1 *}$, D. H. Anderson ${ }^{1}$ and A. J. Duncan ${ }^{2}$ \\ ${ }^{1}$ Genetics and Behavioural Sciences Department, Scottish Agricultural College, West Mains Road, \\ Edinburgh EH9 3JG, UK \\ ${ }^{2}$ Macaulay Land Use Research Institute, Craigiebuckler, Aberdeen AB15 8QH, UK
}

(Received 2 January 1997-Revised 14 May 1997-Accepted Il June 1997)

\begin{abstract}
Within the overall objective of whether ruminants are able to form conditioned aversions (CFA) toward a food flavour associated with the administration of an aversive stimulus which occurs naturally in food plants (oxalic acid, $O A$ ), two specific objectives were tested: (1) whether the rate and degree of formation of CFA are dependent on the dose rate of OA administered and (2) whether the persistence of formed CFA depends on the previous dose rate of OA. Sheep were conditioned to associate the specific flavour of one of two novel foods with either the oral administration of $\mathrm{OA}$ or equivalent placebos. Four dose rates of $\mathrm{OA}$ were tested $(0.06,0.12$, 0.18 and $0.24 \mathrm{~g} / \mathrm{kg}$ sheep live weight per d), with twelve sheep per dose. Each conditioning period lasted for $8 \mathrm{~d}$ and was repeated four times. At the end of each conditioning period the preference for the two flavours was measured in short-term, $20 \mathrm{~min}$ preference tests. The persistence of the CFA was measured at $0,7,21$ and $49 \mathrm{~d}$ after the completion of the conditioning phase with long-term, $3 \mathrm{~h}$ preference tests. The results of the experiment indicated that: (1) the rate and degree of formation of CFA were dependent on the rate of administration of $\mathrm{OA}$; (2) sheep required repeated exposures to the lower dose rates of $\mathrm{OA}$ in order to develop CFA and these CFA did not persist in the absence of continual reinforcement; (3) CFA to the higher dose rates of OA were developed after as little as one exposure and persisted over a period of at least 7 weeks. These findings are consistent with the expectation that ruminants should be able to select a diet which minimizes the risk of consumption of potentially harmful foods, whilst at the same time maintaining a degree of flexibility in their feeding behaviour.
\end{abstract}

Conditioned flavour aversions: Diet selection: Oxalic acid: Sheep

It is generally accepted that herbivores select a diet which maximizes nutrient intake, whilst minimizing ingestion of harmful plant compounds (Westoby, 1974; Belovsky \& Schmitz, 1994). One way of achieving this is through developed behavioural mechanisms which allow them to recognize foods on the basis of their nutritional, as well as other, properties, and select for or against food items according to their positive or negative post-ingestive consequences. It has been suggested that for the most part these behaviours are learned in large herbivores (Provenza, 1995; Kyriazakis, 1997), and that in the case of avoidance of potentially harmful secondary plant compounds, herbivores develop CFA towards foods that are associated with the toxic consequences.

Much of the work on CFA (for reviews see Provenza, 1995, 1996) has used $\mathrm{LiCl}$ as a model 'toxin' to demonstrate the development of learned CFA in ruminants. Whilst this work has elucidated very convincingly such a behavioural mechanism, there is still some doubt as to whether experiments based on $\mathrm{LiCl}$, which operates through stimulation of the emetic system, offer a generalized mechanism for how ruminants learn to avoid foods that contain plant secondary compounds with a wider range of physiological consequences. $\mathrm{LiCl}$ appears to be a strong 
inducer of CFA since a single encounter is capable of inducing CFA among ruminants (e.g. du Toit et al. 1991), and aversions towards it appear to be retained for a long period of time (Thorhallsdottir et al. 1987). The next step is therefore to assess whether CFA develop towards secondary plant compounds that occur naturally in plants and which have the potential of inducing mild negative postingestive consequences. A very limited number of preliminary experiments have so far been conducted in ruminants (Kronberg et al. 1993; Kyriazakis et al. 1997; Pfister et al. 1997) to investigate this relationship and its potential as a mechanism of avoiding harmful compounds.

In the present paper, $\mathrm{OA}$ is used as a 'natural' plant compound to investigate whether sheep are able to develop CFA when the flavour of the food is associated with OA administration. $\mathrm{OA}$ is found in many plants, including fodder beet (Beta vulgaris L.) and Rumex species (Libert \& Franceschi, 1987), consumed by ruminants. Its action at the systemic level involves formation of calcium oxalate crystals in blood capillaries causing direct cellular damage (James \& Butcher, 1972). Formation of calcium oxalate precipitates may also reduce systemic $\mathrm{Ca}$ availability (Vonburg, 1994). Although rumen microbes are known to degrade OA, non-adapted animals may absorb significant amounts of it with potentially toxic consequences (James \& Butcher, 1972). In the current experiment the effects of rate of administration of $\mathrm{OA}$ and the number of repeat exposures to OA on the development, magnitude and persistence of CFA were investigated in sheep.

\section{Materials and methods}

\section{Animals and housing}

Forty-eight female sheep of the Texel $\times$ Greyface breed, born indoors in Spring 1996, were used in this experiment. They had been reared indoors since weaning on a moderate quality pelleted basal food with a CP content of $120 \mathrm{~g} / \mathrm{kg}$ and ME content of $9.4 \mathrm{MJ} / \mathrm{kg}$ fresh food. At the start of the experiment sheep were approximately 3 months old and had a mean LW of 21.3 (SD 4.31) kg. At that time they were penned individually and were given a $\mathrm{LW}$-based allowance of the basal food daily $(30 \mathrm{~g} / \mathrm{kg} \mathrm{LW}$; Kyriazakis \& Oldham, 1993); half of the allowance was offered in the morning (08.00 hours) and half in the afternoon (16.00 hours).

\section{Experimental procedure}

The experimental procedure followed closely the protocol developed by Kyriazakis et al. (1997), where the development of food aversions in sheep towards flavours associated with secondary plant compounds was investigated at a single level of administration.

Experimental natural aversive stimulus. OA was used as the aversive stimulus in this experiment. In a previous experiment (Kyriazakis et al. 1997) it was found that sheep develop mild food aversions towards flavours associated with the administration of $0.12 \mathrm{~g} \mathrm{OA} / \mathrm{kg} \mathrm{LW}$ per $\mathrm{d}$. This dose also represents a typical intake of OA by sheep consuming plants (e.g. Rumex spp.) with a moderate concentration of OA (10 g soluble oxalate $/ \mathrm{kg} \mathrm{DM}$; Libert \& Francheschi, 1987).

Flavours and novel food. The flavours to be associated with the administration of $\mathrm{OA}$ were aniseed and orange (inclusion rate $7.5 \mathrm{~g} / \mathrm{kg}$ ). The two flavours, at this particular inclusion rate, have been found to be equally preferred by sheep (Kyriazakis et al. 1997). Nevertheless, their hedonic acceptability to the sheep used in this trial was tested in a single preference test which lasted for $10 \mathrm{~min}$. First the flavours were mixed with maize starch in a bakery mixer (dilution 1:10) and subsequently each flavour mix was added to the pellets (basal food). The aniseed- and orangeflavoured pellets were offered as a choice to all sheep in a manner similar to the preference tests described later.

A high quality chopped molassed lucerne (Medicago sativa) hay (CP $143 \mathrm{~g} / \mathrm{kg}$ and ME $9.9 \mathrm{MJ} / \mathrm{kg}$ fresh food; DM $860 \mathrm{~g} / \mathrm{kg}$ ) was used as the test food for the sheep. Unflavoured hay was offered to sheep for $3 \mathrm{~d}$ before the experiment for familiarization purposes. During the actual experiment the hay was mixed with either the aniseed or orange flavours, diluted as described earlier.

Conditioning. The four dose rates of $\mathrm{OA}$ used were $0.06,0.12,0.18$ and $0.24 \mathrm{~g} / \mathrm{kg}$ sheep LW per d. OA was delivered orally in gelatin capsules, and the placebos were equivalent empty gelatin capsules.

Sheep were randomly assigned to one of the four OA dose treatments (twelve sheep per treatment). Each conditioning period lasted for $9 \mathrm{~d}$ during which flavours and OA were associated as follows (Table 1). For the first $2 \mathrm{~d}$ of each conditioning period, one of the flavoured hays was offered while dosing with OA (or the placebo). There followed two rest days (days 3 and 4) during which the basal pelleted food was offered at the $30 \mathrm{~g} / \mathrm{kg} \mathrm{LW}$ allowance. For the subsequent $2 \mathrm{~d}$ (days 5 and 6) of the conditioning period the opposite flavoured hay was offered and the animals were dosed with the placebo (or OA). The basal diet was also fed for the last $2 \mathrm{~d}$ of the conditioning period (days 7 and 8). On day 9, preference tests were conducted (see later). The same protocol was followed for each $9 \mathrm{~d}$ conditioning period and was repeated four times. Each animal followed the same flavour-toxin association and order of offering hays throughout the experiment.

The flavoured hays were offered to the sheep from 08.00 to 12.00 hours on conditioning days. At the mid-point of each feeding bout (10.00 hours) sheep were orally dosed with the gelatin capsules. The amount of flavoured hay consumed by sheep was measured over each of the days on which it was offered. On conditioning days, sheep were given the basal food corrected for hay consumption on a DM basis (to achieve $30 \mathrm{~g} / \mathrm{kg} \mathrm{LW}$ allowance) in the afternoon as usual.

Blood samples were taken by jugular venipuncture into evacuated heparinized tubes (Vacutainer, Becton Dickinson, Oxford, Oxon, UK) at 16.00 hours on the second day of each pairing of the flavoured hay with the OA or the placebo, during the conditioning periods (days 2 and 6). The timing of sample collection $(6 \mathrm{~h}$ after the administration of $\mathrm{OA}$ ) was chosen to allow the development of physiological effects (Sanz \& Reig, 1992; Kyriazakis et al. 1997). Plasma samples were stored at $-20^{\circ}$ pending 
Table 1. The conditioning and short-term preference schedule of one conditioning period, offering a unique combination of flavoured hay and oxalic acid (OA) association to four groups of sheep $(n 3)$ per OA dose concentration ${ }^{*}$

\begin{tabular}{|c|c|c|c|c|}
\hline \multirow[b]{2}{*}{ Day } & \multicolumn{4}{|c|}{ Sheep groups on each of the four OA doses $(n 3)$} \\
\hline & 1 & 2 & 3 & 4 \\
\hline $\begin{array}{l}1 \\
2 \\
3 \\
4\end{array}$ & $\begin{array}{l}\text { Aniseed/OA+ } \\
\text { Aniseed/OA+ }\end{array}$ & $\begin{array}{r}\text { Orange/OA- } \\
\text { Orange/OA- } \\
\mathrm{Ba} \\
\mathrm{Ba}\end{array}$ & $\begin{array}{l}\text { Aniseed/OA- } \\
\text { Aniseed/OA- } \\
\text { ood } \\
\text { ood }\end{array}$ & $\begin{array}{l}\text { Orange/OA+ } \\
\text { Orange/OA+ }\end{array}$ \\
\hline $\begin{array}{l}5 \\
6 \\
7 \\
8 \\
9\end{array}$ & $\begin{array}{l}\text { Orange/OA- } \\
\text { Orange/OA- }\end{array}$ & $\begin{array}{r}\text { Aniseed/OA+ } \\
\text { Aniseed/OA+ } \\
\text { Ba } \\
\text { Ba } \\
20 \text { min preference }\end{array}$ & $\begin{array}{l}\text { Orange/OA+ } \\
\text { Orange/OA+ } \\
\text { ood } \\
\text { ood } \\
\text { (orange v. aniseed) }\end{array}$ & $\begin{array}{l}\text { Aniseed/OA- } \\
\text { Aniseed/OA- }\end{array}$ \\
\hline
\end{tabular}

analysis for $\mathrm{Ca}$ (Voth, 1981) and $\mathrm{P}$ concentrations (Kyriazakis et al. 1994). Given the mode of action of OA the expectation was a reduction in the systemic availability of $\mathrm{Ca}$, and hence a reduction in plasma $\mathrm{Ca}$, which would be expected to result in an increase in plasma $P$ concentrations, on the days when OA was administered (James \& Butcher, 1972).

Preference tests. At the end of each conditioning period (day 9) all animals were given a choice between the hays with aniseed and orange flavours (Table 1). These single tests (short-term preference tests) lasted for $20 \mathrm{~min}$ and were conducted in the morning (08.00 hours) of day 9 . To investigate the persistence of CFA, preference tests lasting $3 \mathrm{~h}$ each, were performed at the end of the last conditioning period, and again 7,21 and $49 \mathrm{~d}$ later. Intakes of both flavoured hays during these long-term preference tests were recorded at both $20 \mathrm{~min}$ and $3 \mathrm{~h}$.

Sheep were offered $500 \mathrm{~g}$ aniseed and $500 \mathrm{~g}$ orangeflavoured hay concurrently in separate food boxes in the short-term preference tests, while $1000 \mathrm{~g}$ of each was offered in the long-term preference tests. The position of the flavoured hays was completely randomized across sheep, within each preference test. Preference for a flavour per se, and hence a flavoured hay, was calculated as the intake of the respective flavoured hay relative to total intake during the choice tests: preference ratio = intake of aniseed- or orange-flavoured hay/total intake of flavoured hays (aniseed and orange). Preference could thus be affected by hay flavour, flavour order and OA dose rate, and their respective interactions. Avoidance ratios for $\mathrm{OA}$ associated hays were calculated for each of the four flavour-OA combinations using the following formula: avoidance ratio $=$ intake of hay associated with $O A$ administration/total intake of flavoured hays. Avoidance could thus be affected by OA association, flavour order, OA dose rate, and their respective interactions.

\section{Statistical analysis}

Since the experiment consisted of either four identical (conditioning) periods, or four similar short- and long-term preference tests, it was analysed as a split-plot design in time (Horgan \& Sword, 1995) with the food (OA or placebo associated), OA dose concentration $(0.06,0.12$, 0.18 and $0.24 \mathrm{~g} / \mathrm{kg} \mathrm{LW}$ per d), flavour (aniseed or orange), flavour presented first (flavour order) and period as the main effects, with individual sheep nested within treatments. This was the case for the analyses of preference and avoidance ratios during the short- and long-term preference test, and the physiological variables measured. For hay intake during the conditioning phase, where more than one measurement was taken within a conditioning period, the nesting structures used were conditioning phase within individual sheep, and intake within individual sheep. Data were tested for compound symmetry (i.e. that the variability in response was the same for all treatments) and to ensure that correlation between two factor levels was the same for all pairs (Horgan \& Sword, 1995) before analysis, and these conditions were met.

\section{Results}

\section{Hedonic acceptability}

Sheep demonstrated a similar preference for the pelleted (basal) food flavoured with aniseed $(55 \%)$ or with orange $(45 \%)(P>0.1)$ during the hedonic acceptability tests. The actual intakes of flavoured pellets were 70 (SE 9.3) v. 53 (SE 8.0) $\mathrm{g} / 10 \mathrm{~min}$ for aniseed- and orange-flavoured pellets respectively.

\section{Intake of flavoured hay over successive conditioning periods}

There was a highly significant interaction between OA dose rate and conditioning period $(P<0.001)$ on the intake of hays (Table 2). This was due to the fact that for the highest $\mathrm{OA}$ rate $(0.24 \mathrm{~g} / \mathrm{kg} \mathrm{LW}$ per d) hay intake increased only from the 1 st to the 2 nd conditioning period; it subsequently declined between the 2 nd and 4 th conditioning periods. For sheep on the other three OA dose rates hay intake rose systematically (from 1 st to 4 th conditioning period). There 
Table 2. Intake of flavoured hay $(g / 4 \mathrm{~h})$ by sheep receiving different concentrations of oxalic acid $(O A ; g / \mathrm{kg}$ live weight per d) during each of four conditioning periods $\nmid \ddagger$

\begin{tabular}{|c|c|c|c|c|c|c|}
\hline \multicolumn{7}{|c|}{ OA concentration ( $\mathrm{g} / \mathrm{kg}$ live weight per $\mathrm{d}$ ) } \\
\hline & 0.06 & 0.12 & 0.18 & 0.24 & & Mean \\
\hline \multicolumn{7}{|c|}{ Conditioning period } \\
\hline $1 \mathrm{st}$ & 209 & 228 & 240 & 243 & & 255 \\
\hline 2nd & 418 & 277 & 343 & 327 & & 341 \\
\hline $3 \mathrm{rd}$ & 514 & 338 & 445 & 326 & & 406 \\
\hline 4th & 593 & 437 & 528 & 299 & & $\begin{array}{c}464 \\
\text { (SED } 45 \cdot 6)\end{array}$ \\
\hline Mean & 458 & 320 & 389 & 299 & (SED 55.1) & 367 \\
\hline \multicolumn{7}{|c|}{ Significance of: } \\
\hline \multicolumn{6}{|c|}{$\mathrm{OA}$ administration } & NS \\
\hline \multirow{2}{*}{\multicolumn{6}{|c|}{$\begin{array}{l}\text { OA dose rate } \\
\text { Conditioning period }\end{array}$}} & * \\
\hline & & & & & & $\star \star \star \star$ \\
\hline \multicolumn{6}{|c|}{$O A$ administration $\times$ dose rate } & NS \\
\hline \multirow{2}{*}{\multicolumn{6}{|c|}{$\begin{array}{l}\text { OA administration } \times \text { conditioning period } \\
\text { OA dose rate } \times \text { conditioning period }\end{array}$}} & NS \\
\hline & & & & & & $* * *$ \\
\hline \multicolumn{6}{|c|}{$\begin{array}{l}\text { OA administration } \times \text { dose rate } \times \text { condi- } \\
\text { tioning }\end{array}$} & NS \\
\hline
\end{tabular}

- $P<0.05,{ }^{* \star *} P<0.001$.

fFor details of the conditioning periods, see Table 1

\$ The intake of flavoured hay was not affected by flavour used (orange or aniseed), or the presentation order of the toxin, or by its interaction with any of these.

was also a significant main effect of dose rate of OA on hay intake $(P<0.05)$. Hay intake was lowest and highest in the two extreme $(0.24$ and $0.6 \mathrm{~g} / \mathrm{kg} \mathrm{LW}$ per d) OA dose rates respectively; this was particularly the case for the last two conditioning periods. There was no overall effect of $\mathrm{OA}$ administration, flavour or flavour order on hay consumed during the four conditioning periods.

\section{Effects on the physiological variables measured during conditioning periods}

There was a highly significant effect of conditioning period on plasma concentrations of both $\mathrm{Ca}$ and $\mathrm{P}$ in blood samples taken $6 \mathrm{~h}$ after the administration of OA. Plasma concentrations of $\mathrm{P}$ declined as conditioning progressed: 79, 73, 69 and 67 (SED $1.60 ; P<0.001$ ) $\mathrm{mg}$ $\mathrm{P} / 1$, whereas no specific patterns were seen in the plasma concentration of $\mathrm{Ca}$ : 102, 106, 104 and 103 (SED 1.04; $P<0.05) \mathrm{mg} \mathrm{Ca} / \mathrm{l}$ for the $1 \mathrm{st}$ to the 4 th conditioning period respectively. There were no significant interactions between conditioning period and either $\mathrm{OA}$ administration or $O A$ dose rate.

Given the absence of these interactions, the effects of the $\mathrm{OA}$ administration and dose rate on plasma concentrations of $\mathrm{Ca}$ and $\mathrm{P}$ are shown in Table 3. OA administration did not significantly affect plasma concentrations of either $\mathrm{Ca}$ or $\mathrm{P}$. There was, however, a significant interaction between $\mathrm{OA}$ administration and dose rate on plasma $\mathrm{Ca}$ concentration $(P<0.05)$ and a significant effect of $O A$ dose rate on plasma $P$ concentration $(P<0 \cdot 05)$. When $\mathrm{OA}$ was administered the trend was for plasma $\mathrm{Ca}$ concentration to decrease and plasma $P$ concentration to increase with increasing $\mathrm{OA}$ dose rate. There were no such trends for
Table 3. Mean effects of oxalic acid (OA) administration $(O A+)$ or placebos (controls, $\mathrm{OA}_{-}$) ) on the plasma concentrations of calcium and phosphorus $(\mathrm{mg} / \mathrm{l})$ in sheep $\dagger$

(Mean values for three sheep)

\begin{tabular}{|c|c|c|c|c|}
\hline & \multicolumn{2}{|c|}{$\mathrm{Ca}(\mathrm{mg} / \mathrm{l})$} & \multicolumn{2}{|c|}{$P(m g / l)$} \\
\hline & $\mathrm{OA}+$ & $\mathrm{OA}-$ & OAt & $\mathrm{OA}-$ \\
\hline Concentration ( $g / \mathrm{kg}$ live wt per $\mathrm{d}$ ) & & & & \\
\hline $\begin{array}{l}0.06 \\
0.12 \\
0.18 \\
0.24\end{array}$ & $\begin{array}{r}107.8 \\
105.8 \\
104.1 \\
98 \cdot 6\end{array}$ & $\begin{array}{l}104 \cdot 7 \\
103 \cdot 4 \\
103 \cdot 8 \\
102 \cdot 3\end{array}$ & $\begin{array}{l}65 \cdot 7 \\
71.0 \\
77.5 \\
75.4\end{array}$ & $\begin{array}{l}76 \cdot 0 \\
68.0 \\
66.6 \\
76.5\end{array}$ \\
\hline SED & \multicolumn{2}{|c|}{2.72} & \multicolumn{2}{|c|}{4.86} \\
\hline $\begin{array}{l}\text { Significance of: } \\
\text { OA administration } \\
\text { OA dose rate } \\
\text { OA administration } \times \text { dose rate }\end{array}$ & \multicolumn{2}{|c|}{$\begin{array}{l}\text { NS } \\
\text { NS }\end{array}$} & \multicolumn{2}{|c|}{$\begin{array}{l}\text { NS } \\
{ }^{*} \\
\text { NS }\end{array}$} \\
\hline
\end{tabular}

${ }^{*} P<0.05$.

† There were four concentrations of $O A$ administered: $0.06,0.12,0.18$ and $0.24 \mathrm{~g} / \mathrm{kg}$ live weight per $d$. The blood samples were taken $6 \mathrm{~h}$ after the oral administration of $O A$ or placebo.

either plasma $\mathrm{Ca}$ or $\mathrm{P}$ concentration when no $\mathrm{OA}$ was administered (controls).

\section{Avoidance of flavoured hay associated with oxalic acid administration}

(1) Tests at the end of each conditioning period (short-term preference tests). The total intake of hay over the $20 \mathrm{~min}$ preference tests was significantly affected by the interaction between OA dose rate and conditioning period $(P<0.001)$. This was due to lower intakes associated with high dose rates of $\mathrm{OA}$ during the 4 th conditioning period (average intakes 140,134, 145 and 85 (SED 21.1) g/20 min for the four $\mathrm{OA}$ dose rates respectively). Total hay intake increased in successive conditioning periods $(P<0.001)$ (with the exception of the highest OA dose rate in the 4th test). Mean hay intakes were $80,92,140$ and 126 (SED 7.27) $\mathrm{g} / 20 \mathrm{~min}$ for the four tests respectively.

Preference ratios for flavoured hays were significantly affected by the interaction between conditioning period and type of flavour used (aniseed or orange) $(P<0.05)$. Thus, there were cases where preference was affected by flavour (in these cases aniseed-flavoured was preferred over orange-flavoured hay), and cases where preference was equal between the two flavours. These effects, however, were not systematic with conditioning (e.g. as conditioning progressed). No other interactions with flavour had a significant effect on preference.

Avoidance ratios for the hay associated with OA administration are shown in Table 4. These are given for each of the four preference tests performed at the end of each conditioning period, and for each of the four OA dose rates used. Avoidance for a hay was significantly or tended $(0.1 \leq P<0.05)$ to be affected by: its previous association with $\mathrm{OA}$ administration $(P<0.05)$, conditioning period $(P<0.05)$, and the interactions between $\mathrm{OA}$ association $x$ dose rate $(P \leq 0 \cdot 1)$, OA association $\times$ conditioning period $(P<0.01)$ and OA dose rate $\times$ conditioning period $(P \leq 0 \cdot 1)$. All these effects (interactions) are shown in 
Table 4. The mean avoidance ratiosł for the food associated with oxalic acid (OA) administration, during short-term preference tests performed at the end of each of four conditioning periods $\S \|$

\begin{tabular}{|c|c|c|c|c|c|c|}
\hline & \multicolumn{4}{|c|}{ OA concentration ( $\mathrm{g} / \mathrm{kg}$ live weight per $\mathrm{d}$ ) } & & \multirow[b]{2}{*}{ Mean } \\
\hline & 0.06 & 0.12 & 0.18 & 0.24 & & \\
\hline \multicolumn{7}{|c|}{ Conditioning period } \\
\hline 1st & 0.628 & 0.623 & 0.475 & 0.314 & & 0.510 \\
\hline 2nd & 0.481 & 0.582 & 0.414 & 0.449 & & 0.482 \\
\hline 3rd & 0.400 & 0.550 & 0.280 & 0.405 & & 0.409 \\
\hline 4th & 0.465 & 0.337 & 0.330 & 0.274 & & $\begin{array}{c}0.352 \\
\text { (SED } 0.0516)\end{array}$ \\
\hline Mean & 0.494 & 0.523 & 0.375 & 0.360 & (SED 0.772) & 0.438 \\
\hline \multicolumn{7}{|c|}{ Significance of: } \\
\hline \multicolumn{6}{|c|}{ OA association } & * \\
\hline \multirow{2}{*}{\multicolumn{6}{|c|}{$\begin{array}{l}\text { OA dose rate } \\
\text { Conditioning period }\end{array}$}} & NS \\
\hline \multirow{2}{*}{\multicolumn{6}{|c|}{$\begin{array}{l}\text { Conditioning period } \\
\text { OA association } \times \text { dose rate }\end{array}$}} & $*$ \\
\hline & & & & & & $\dagger$ \\
\hline \multirow{2}{*}{\multicolumn{6}{|c|}{$O A$ association $\times$ conditioning period }} & ** \\
\hline \multirow{2}{*}{\multicolumn{6}{|c|}{$\begin{array}{l}\text { OA dose rate } \times \text { conditioning period } \\
\text { OA association } \times \text { dose rate } \times \text { conditioning period }\end{array}$}} & + \\
\hline & & & & & & NS \\
\hline
\end{tabular}

- $P \leq 0.05,{ }^{* \star} P \leq 0.01,+P \leq 0.1$

¥ Low ratios represent avoidance of the OA-associated food.

$\S$ For details of conditioning periods, see Table 1.

\| $O A$ was administered at four different dose concentrations and was associated with a particular flavoured hay. The presentation order of the toxin and its interactions with other variables did not significantly affect the avoidance ratios.

Table 4. The interactions between $O A$ dose rate and conditioning period (Table 4) imply that whilst association with OA administration led to aversions, these were not developed at the same rate for each dose rate. No aversion seemed to have developed on the lowest OA concentration $(0.06 \mathrm{~g} / \mathrm{kg} \mathrm{LW}$ per d), whereas aversions appeared to develop progressively earlier on the $0.12,0.18$ and 0.24 $\mathrm{g} / \mathrm{kg} \mathrm{LW}$ per d dose-rate treatments respectively.

(2) Tests after the completion of conditioning (persistence tests). Total food intake during the $3 \mathrm{~h}$ preference tests was significantly affected only by the time of the persistence test and by $\mathrm{OA}$ dose rate. Total food intake increased over successive tests: $428,461,528$ and 554 (SED $21.9 ; P<0.001$ ) $\mathrm{g} / 3 \mathrm{~h}$ for the tests performed at 0 , 7,21 and $49 \mathrm{~d}$ after the completion of conditioning respectively. Total food intake was significantly lower for the sheep on the highest OA dose rate : 565, 485, 540, 382 (SED $55.5 ; P<0.05$ ) $\mathrm{g} / 3 \mathrm{~h}$ for the four dose rates respectively. There were no significant interactions between the time of persistence test and OA dose rate.

Preferences and aversions during these tests were measured both in the short $(20 \mathrm{~min})$ and longer run $(3 \mathrm{~h})$. Because of the relatively high correlations between these two measurements $(r+0.836)$, only the results from the $3 \mathrm{~h}$ tests are reported here. The relationship between AR measured over $20 \mathrm{~min}$ and $3 \mathrm{~h}$ was described by the following equation:

$$
\begin{gathered}
\text { AR (over } 20 \mathrm{~min})=0.045+0.915 \times \mathrm{AR} \text { (over } 3 \mathrm{~h}) \\
(\mathrm{SE} 0.0219)(\mathrm{SE} 0.0440) \\
\text { residual SD }(\mathrm{RSD}) 0.182 .
\end{gathered}
$$

Given that the intercept of this equation was not significantly different from zero, the relationship could be as well represented by:

$$
\begin{gathered}
\mathrm{AR}(\text { over } 20 \mathrm{~min})=0.987 \times \mathrm{AR}(\text { over } 3 \mathrm{~h}), \quad \text { RSD } 0.184 . \\
(\mathrm{SE} 0.0269)
\end{gathered}
$$

Preference for the flavoured hay was strongly affected by the interactions between time of the test and type of flavour used $(P<0.001)$. No other interactions with flavour had a significant effect on preference.

Avoidance ratios measured at $0,7,21$ and $49 \mathrm{~d}$ after the completion of conditioning for the hay associated with $O A$ administration are shown in Table 5. Avoidance ratios for a hay were or tended $(0.1 \leq P<0.05)$ to be affected only by its previous association with OA $(P<0.01)$, OA dose rate $(P<0.1)$, time of test $(P<0.001)$ and the interaction between $\mathrm{OA}$ association $\times$ time of test $(P<0 \cdot 1)$. The effect of association with OA administration implies that sheep discriminated against the hay associated with OA (overall avoidance ratio $=0.394$ ). The interaction between $O A$ dose rate $\times$ time of test (Table 5), implies that whilst association with OA administration led to aversions, these were not persistent to the same degree for each dose rate. The effect of OA dose rate was largely due to the strong avoidance ratios observed on the highest $\mathrm{OA}$ dose concentration $(0.24 \mathrm{~g} / \mathrm{kg} \mathrm{LW}$ per d dose rate), at all times of performance of the tests. The aversions developed on the 0.12 and $0.18 \mathrm{~g} / \mathrm{kg} \mathrm{LW}$ per $\mathrm{d}$ dose rates, which were evident on day 0 of the tests, did not persist after the completion of $\mathrm{OA}$ conditioning. 
Table 5. The mean avoidance ratios $\neq$ for the food associated with oxalic acid $(O A)$ administration, during long-term preference tests ( $3 \mathrm{~h}$ duration) in sheep performed on days $0,7,21,49$ after the completion of conditioning\$

\begin{tabular}{|c|c|c|c|c|c|c|}
\hline & \multicolumn{4}{|c|}{ OA concentration ( $\mathrm{g} / \mathrm{kg}$ live weight per $\mathrm{d}$ ) } & & \multirow[b]{2}{*}{ Mean } \\
\hline & 0.06 & 0.12 & 0.18 & 0.24 & & \\
\hline \multicolumn{7}{|c|}{ Time of test (d) } \\
\hline 0 & 0.450 & 0.373 & 0.353 & 0.201 & & 0.344 \\
\hline 7 & 0.462 & 0.402 & 0.495 & 0.342 & & 0.425 \\
\hline 21 & 0.421 & 0.535 & 0.467 & 0.268 & & 0.423 \\
\hline 49 & 0.489 & 0.434 & 0.359 & 0.247 & & $\begin{array}{c}0.382 \\
\text { (SED } 0.0356 \text { ) }\end{array}$ \\
\hline Mean & 0.456 & 0.436 & 0.418 & 0.265 & (SED 0.0988) & 0.394 \\
\hline \multicolumn{7}{|c|}{ Significance of: } \\
\hline OA as & & & & & & ** \\
\hline OA do & & & & & & $\dagger$ \\
\hline Time & & & & & & 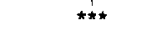 \\
\hline \multicolumn{6}{|c|}{ OA association $\times$ dose rate } & NS \\
\hline \multicolumn{6}{|c|}{$\mathrm{OA}$ association $\times$ time of test } & + \\
\hline \multirow{2}{*}{\multicolumn{6}{|c|}{$\begin{array}{l}\text { OA rate } \times \text { time of test } \\
\text { OA association } \times \text { dose rate } \times \text { time of test }\end{array}$}} & NS \\
\hline & & & & & & NS \\
\hline
\end{tabular}

$* P \leq 0.01, * * P \leq 0.001, \dagger P \leq 0.1$.

Low ratios represent avoidance of the $O A$-associated foods.

$\S$ For details of conditioning periods, see Table 1 .

|| During conditioning $O A$ was administered at four different dose concentrations and was associated with a particular flavoured hay. The presentation order of the toxin and its interactions with other variables did not significantly affect the avoidance ratios.

\section{Discussion}

The objective of the experiment was to test the hypothesis that large herbivores, in this case sheep, are able to form CFA toward food flavours associated with the administration of a detrimental plant component, OA, which occurs naturally in food plants. Two particular questions were addressed: (1) are the rate and degree of development of CFA dependent on the dose rate of OA and hence the strength of the negative post-ingestive consequences elicited by its administration, and (2) is the persistence of formed CFA dependent on the strength of the aversive stimulus? To address these questions we varied the strength of the aversive stimulus and quantified the post-ingestive consequences of $\mathrm{OA}$ administration by monitoring two physiological variables (plasma $\mathrm{Ca}$ and $\mathrm{P}$ concentrations) in blood samples taken $6 \mathrm{~h}$ after OA administration.

The observed effects on plasma $\mathrm{Ca}$ and $\mathrm{P}$ concentrations during $\mathrm{OA}$ administration days were in the expected direction and dose-dependent, and showed the expected complementarity between $\mathrm{Ca}$ and $\mathrm{P}$ levels (Table 3). The main effect of $\mathrm{OA}$ administration, compared with placebo days, was seen as mild hypocalcaemia in animals given the highest dose rate of $\mathrm{OA}(0.24 \mathrm{~g} \mathrm{OA} / \mathrm{kg} \mathrm{LW}$ per d). The fact that the differences were not as clear between the samples taken after administration of $\mathrm{OA}$ and placebos at the other $\mathrm{OA}$ dose rates, might be due to some residual effects of $\mathrm{OA}$ administration being carried over, despite the fact that a $2 \mathrm{~d}$ rest period was allowed between administration and placebo days. In the experiment of Kyriazakis et al. (1997) where larger sheep were used, a mild but similarly significant hypocalcaemia was observed at a dose of $0.12 \mathrm{~g} / \mathrm{kg} \mathrm{LW}$ per $\mathrm{d}$. The difference in the effects of OA between the two experiments might lie in the fact that sheep in the current experiment consumed more lucerne hay on a LW basis than in the previous experiment. Lucerne contains significant amounts of $\mathrm{Ca}$ salts which complex with $\mathrm{OA}$ in the gut rendering it unavailable (discussed by Frutos et al. 1998). This effect would have been greater for the small sheep in the current experiment (given the LW-based dose of $\mathrm{OA}$ ).

\section{Development of conditioned flavour aversions}

Given the physiological consequences of $\mathrm{OA}$ administration, the expectation was that if CFA were to develop then these would form faster and be stronger for the food flavour which was associated with the highest $\mathrm{OA}$ dose rate. We were also expecting that formed aversions would not be affected by the flavour used to create the associations between flavour and $\mathrm{OA}$ administration, i.e. the preference ratios would be equal for the two flavours used. This expectation was based on the fact that the hedonic acceptability of the basal food flavoured with aniseed or orange was equal during the $10 \mathrm{~min}$ preliminary test (the duration of this test was relatively short because we did not want to over-familiarize the animals with the flavours). Some preference ratios were affected by the type of flavour used; but given that this was not systematic between tests and the initial equal acceptability of both flavours, we suggest that their significance was spurious.

The interactions between OA dose rate and conditioning period implied that CFA did not develop at the same rate for each dose rate. Furthermore the rate of development appeared to be systematic. No aversions developed at the lowest OA rate, whereas they were formed after only one conditioning phase at the highest $O A$ concentration. Aversions also appeared to have developed for the intermediate dose concentrations, but their rate of devel- 
opment was also somewhat intermediate. From these results we conclude that the rate of aversion formation depends on the dosage of the aversion stimulus. This implies that for a compound such as OA, whose effects are acutely 'toxic' only above a certain threshold level (Duncan et al. 1998), animals might need repeated exposure to its subclinical consequences in order to develop CFA. How animals develop CFA to flavours that are not associated with overt physiological consequences still remains an interesting question, which cannot be answered by our experiment.

Our present experiment differs from convention in that animals underwent a repeated conditioning schedule. Most frequently, experimental formation of CFA in ruminants is tested after only one conditioning event. Their formation in these cases probably reflects the strong consequences of the model 'toxin' used in the investigations $(\mathrm{LiCl}$; e.g. Thorhallsdottir et al. 1987; du Toit et al. 1991; Launchbaugh \& Provenza, 1994). The conditioning schedule used is likely, therefore, to influence the conclusions drawn in future investigations on the development of CFA to natural secondary plant compounds and its significance as a behavioural mechanism that influences ruminant diet selection. In laboratory animals, however, repeated conditioning schedules have been used (e.g. Bhardwaj \& Prakash, 1979), and their findings on the pattern of development of conditioned aversions to poisons are similar to those of our experiment.

The experimental design further allowed investigation of the strength of the developed CFA as a function of the OA dose rate. If such a comparison is made at the 4th conditioning test, where sheep had developed aversions in three out of the four doses used (Table 4), then there is an indication that avoidance ratio was lowest, and hence aversion stronger, at the highest dose concentration. This relationship, however, does not appear to be linear, as found in the experiment of du Toit et al. (1991) (at least once the toxin used had exceeded a certain threshold). Avoidance ratios were relatively weak indicating the development of 'mild' aversions in our experiment (ranging from 0.34 to 0.27 during the 4 th conditioning test). These contrast with the strong avoidance ratios observed where $\mathrm{LiCl}$ was used as the experimental toxin. At high $\mathrm{LiCl}$ doses, avoidance ratios were very low, i.e. $<0.10$ (e.g. du Toit et al. 1991; O'Connor \& Matthews, 1995). The explanation for this apparent difference might lie in the magnitude of the physiological consequences achieved by $\mathrm{LiCl}$ and $\mathrm{OA}$ administrations. In our experiment the objective was to mimic the physiological impact of naturally consumed plants. Indeed OA administration was not followed by any obvious signs of 'distress' in the sheep, with the exception of those on the highest dose where a transient and mild inappetance followed the $2 \mathrm{~d}$ of OA administration. A continuous, but small scale, consumption of the food associated with relatively mild toxic consequences might be beneficial under grazing conditions (Cooper et al. 1995). The concentrations of toxins in food plants change with time as a result of plant growth processes and previous herbivory and the physiological consequences may also alter as herbivores adapt to the secondary compounds in their diets (Feeny, 1976; Allison et al. 1977; Provenza et al. 1992; Frutos et al. 1998). Thus by developing only mild aversions to foods associated with mild negative post-ingestive consequences, animals might be able to maintain an effective sampling behaviour, whilst the consumption of the toxin is kept below a threshold.

\section{Persistence of conditioned flavour aversions}

The second question addressed by the experiment was whether the degree of persistence (i.e. rate of extinction) of developed CFA depended on the dose concentration of OA. The tests of persistence were conducted after the completion of conditioning and in the absence of any continuous negative post-ingestive consequences. The feeding behaviour of the sheep, i.e. avoidance ratios, was recorded both in the short $(20 \mathrm{~min})$ and longer term $(3 \mathrm{~h})$, in order to observe any differences in the CFA time scale, within a test. It is possible that in the short term, i.e in the first few minutes, the feeding behaviour of the sheep is influenced by trivial events, such as the position of the feeds etc. Longer term tests are likely to provide more convincing evidence of biologically significant behaviour (Kyriazakis, 1997). Tests were kept short during the conditioning phase to avoid giving animals excessive amounts of test feeds without their associated post-ingestive consequences. The close association between avoidance ratios measured over $20 \mathrm{~min}$ and over $3 \mathrm{~h}$ during the persistence tests suggests that sheep were able to make appropriate choices over short time-scales.

The observed avoidance ratios suggested that only sheep on the highest $O A$ dose rates continued to demonstrate aversions towards the flavour previously associated with the administration of $O A$ up to $49 \mathrm{~d}$ after the last conditioning. Since the avoidance ratios ranged between 0.201 and 0.247 (SED 0.116) for the tests performed at 0 and $49 \mathrm{~d}$ respectively, it is suggested that the formed CFA on this dose rate were very robust. For all other dose concentrations the avoidance ratios were consistently above 0.40 and not significantly different from indifference (avoidance ratio 0.50 ), for the tests performed at 7,21 and 49 days. This implies that at 'normal' or 'mild' concentrations of $\mathrm{OA}$ any formed CFA would be easily extinguished. This may have adaptive significance, allowing the animal optimum flexibility in dietary habits, along the lines discussed earlier, given the temporal and spatial variability in toxin concentrations in plants (Belovsky \& Schmitz, 1994), and it is consistent with other observations (Frutos et al. 1998; Kyriazakis et al. 1997). Nevertheless, there is the opposing view in the literature, which suggests that young ruminants can remember foods that produced positive or negative post-ingestive consequences for at least 1-3 years without any intervening exposure (e.g. Kendrick, 1992). These latter results of course might depend on the extent of the post-ingestive consequences associated with the CFA, in a way similar to the CFA observed for the highest OA dose in our experiment. It is plausible to suggest that within the 'normal' grazing behaviour of the animals CFA should have a flexible occurrence and hence be easily extinguished. 


\section{Conclusians}

The experiment demonstrates that sheep are able to form conditioned aversions towards a flavour that is associated with the administration of a secondary compound which occurs naturally in plants, and has the potential of inducing negative post-ingestive consequences. The rate and degree of formation of such aversions are dependent on the quantity of the secondary compounds ingested, and these effects are probably mediated through the magnitude of the induced post-ingestive consequences. Mild consequences lead to the formation of mild aversions, in the sense that sheep continue to consume considerable amounts of the aversive food, and CFA of this type do not persist in the absence of continuous, negative post-ingestive consequences. More acute 'toxicity' leads to aversions after as little as one exposure to the aversive stimulus in question and these aversions persist for a relatively long period (in the case of this experiment up to 7 weeks). The behaviours observed in this experiment are consistent with the expectation that herbivores should select a diet which minimizes the risk of consumption of potentially harmful foods, whilst at the same time maintaining a degree of flexibility in their feeding behaviour.

\section{Acknowledgements}

We are grateful to T. McHale and S. Young for their expert technical assistance. Both the Scottish Agricultural College and the Macaulay Land Use Research Institute receive funding from the Scottish Office Agriculture, Environment and Fisheries Department. International Additives Ltd, Wallasey, UK advised on and kindly donated the flavours used.

\section{References}

Allison MJ, Littledike ET \& James LF (1977) Changes in ruminal oxalate degradation rates associated with adaptation to oxalate ingestion. Journal of Animal Science 45, 1173-1179.

Belovsky GE \& Schmitz OJ (1994) Plant defenses and optimal foraging by mammalian herbivores. Joumal of Mammalogy 75 , 818-832.

Bhardwaj D \& Prakash I (1979) Intensity of poison aversion and bait shyness in Rattus rattus due to intermittent and successive exposure to RH-787. Zeitschrift angewandter Zoologie 66, 427436.

Cooper SDB, Kyriazakis I \& Nolan JV (1995) Diet selection in sheep: the role of the rumen environment on the selection of a diet from two feeds that differ in their energy density. British Journal of Nutrition 74, 39-54.

du Toit JT, Provenza FD \& Nartis AS (1991) Conditioned food aversions: how sick must a ruminant get before it detects toxicity in foods. Applied Animal Behavioural Science 30, 35-46.

Duncan AJ, Frutos P \& Young SA (1998) Rates of oxalic acid degradation in the rumen of sheep and goats in response to different levels of oxalic acid administration. Joumal of Chemical Ecology (In the Press).

Feeny P (1976) Plant apparency and chemical defense. Recent Advances in Phytochemistry 10, $1-40$.

Frutos P, Duncan AJ, Kyriazakis I \& Gordon IJ (1998) Learned aversion towards oxalic acid-containing foods by goats: does rumen adaptation to oxalic acid influence diet choice? Joumal of Chemical Ecology (In the Press).

Horgan GW \& Sword AM (1995) Statistical Methods for Repeated Measures Data. Edinburgh: Biomathematics \& Statistics Scotland, University of Edinburgh.

James LF \& Butcher JE (1972) Halogeton poisoning of sheep: effect of high level of oxalate intake. Journal of Animal Science 35, $1233-1240$.

Kendrick KM (1992) Cognition. In Farm Animals and the Environment, pp. 209-231 [C Phillips and D Piggins, editors]. Oxford: CAB INTERNATIONAL.

Kronberg SL, Muntifering RB, Ayers EL \& Marlow CB (1993) Cattle avoidance of leafy spurge: a case of conditioned aversion. Journal of Range Management 46, 364-366.

Kyriazakis I (1997) The nutritional choices of farm animals: to eat or what to eat? In: Animal Choices. Occasional Publication of the British Society of Animal Science no. 20, pp. 55-65 [MJ Forbes and MA Varley, editors]. Edinburgh: BSAS.

Kyriazakis I \& Oldham JD (1993) Diet selection in sheep: the ability of growing lambs to select a diet that meets their crude protein requirements. British Joumal of Nutrition 69, 617-629.

Kyriazakis I, Oldham JD, Coop RL \& Jackson F (1994) The effect of subclinical intestinal nematode infection on the diet selection of growing sheep. British Journal of Nutrition 72, 665-677.

Kyriazakis I, Papachristou TG, Duncan AJ \& Gordon IJ (1997) Mild conditioned food aversions developed by sheep towards flavours associated with plant secondary compounds. Journal of Chemical Ecology 23, 727-746.

Launchbaugh KL \& Provenza FD (1994) The effect of flavour concentration and toxin dose on the formation and generalisation of flavour aversions in lambs. Journal of Animal Science 72, 10-13.

Libert B \& Franceschi R (1987) Oxalate in crop plants. Journal of Agriculture and Food Chemistry 35, 926-938.

O'Connor CE \& Matthews LR (1995) Cyanide induced aversions in the possum (Trichosurus vulpecula): effect of route of administration, dose and formulation. Physiology and Behavior 58, 265-271.

Pfister JA, Provenza FD, Manners GD, Gardner DR \& Ralphs MH (1997) Tall larkspur ingestion: can cattle regulate intake below toxic levels? Joumal of Chemical Ecology 23, 759-777.

Provenza FD (1995) Postingestive feedback as an elementary determinant of food preference and intake in ruminants. Joumal of Range Management 48, 2-17.

Provenza FD (1996) Acquired aversions as the basis for varied diets of ruminants foraging on rangelands. Joumal of Animal Science 74, 2010-2020.

Provenza FD, Pfister JA \& Cheney CD (1992) Mechanisms of learning in diet selection with reference to phytotoxicosis in herbivores. Journal of Range Management 45, 36-45.

Sanz P \& Reig R (1992) Clinical and pathological findings in fatal plant oxalosis. A review. American Journal of Forensic Medicine and Pathology 13, 342-345.

Thorhallsdottir AG, Provenza FD \& Balph DF (1987) Food aversion learning in lambs with or without a mother: discrimination, novelty and persistence. Applied Animal Behaviour Science 18, 327-340.

Vonburg R (1994) Oxalic-acid and sodium oxalate. Joumal of Applied Toxicology 14, 233-237.

Voth LM (1981) Determination of calcium and magnesium in blood serum by automated flame microsampling. Varian Atomic Absorption 44-15, 1-4.

Westoby M (1974) An analysis of diet selection by large generalist herbivores. American Naturalist 108, 290-304. 